\title{
The effect of intermittent hypoxia and fecal microbiota of OSAS on genes associated with colorectal cancer
}

\author{
Jia Gao ${ }^{1,2} \cdot$ Hailong Cao ${ }^{1} \cdot$ Qiang Zhang ${ }^{2} \cdot$ Bangmao Wang ${ }^{1}$
}

Received: 2 December 2019 / Revised: 31 August 2020 / Accepted: 22 September 2020 / Published online: 7 October 2020

(C) The Author(s) 2020

\begin{abstract}
Purpose Colorectal cancer (CRC) is one of the common causes of cancer death worldwide. Obstructive sleep apnea syndrome (OSAS), sharing many risk factors in common with CRC, is prevalent among CRC patients. OSAS may promote the CRC development independently but the mechanism is still unknown. Intermittent hypoxia (IH) is one of the characteristics of OSAS, and hypoxia may influence the genes associated with CRC. Intestinal microbiota plays important role in CRC carcinogenesis, and OSAS patients have been shown to have intestinal microbiota dysbiosis. We hypothesized that IH and intestinal microbiota dysbiosis may be involved for CRC in patients with OSAS.

Methods We established precancerous cell models of CRC with Immorto-Min colonic epithelial (IMCE) cells. First, the cells were exposed to IH in a special chamber for $4 \mathrm{~h}, 8 \mathrm{~h}$, and $12 \mathrm{~h}$. Feces from 6 patients with OSAS and 6 healthy controls were collected and made into sterile fecal fluid for incubation with IMCE cells for $12 \mathrm{~h}$. The cells were then exposed to IH for $4 \mathrm{~h}, 8 \mathrm{~h}$, and $12 \mathrm{~h}$. After IH exposure, the expressions of genes and inflammation cytokines associated with CRC, such as $\beta$-catenin, STAT3, HIF-1 $\alpha$, IL-6, TNF- $\alpha$, c-myc, and cyclinD1, were tested.

Results IH activated the expression of HIF- $1 \alpha$ and STAT3 both in mRNA and protein level (HIF- $1 \alpha: P=0.015$ for mRNA level, $P=0.027$ for protein level; STAT3: $P=0.023$ for mRNA level, $P=0.023$ for protein level), and promoted $\mathrm{p}$-STAT3 shifting to the nucleus $(P=0.023)$. The mRNA of $\beta$-catenin $(P=0.022)$ and cyclinD1 $(P=0.023)$ was elevated, but there was no change for the $\beta$-catenin protein in the nucleus. Gut microbiota of OSAS patients promoted the expression of STAT3 (protein level: $0 \mathrm{~h}: P=$ $0.037 ; 4$ h: $P=0.046 ; 8$ h: $P=0.049 ; 12$ h: $P=0.037$ ), promoted p-STAT3 ( 4 h: $P=0.049 ; 8$ h: $P=0.046 ; 12$ h: $P=0.046)$ shifting to the nucleus, and also elevated the expression of IL-6 and TNF- $\alpha$ in mRNA level at $4 \mathrm{~h}$ (IL-6: $P=0.037$, TNF- $\alpha: P=$ 0.037 ) and $8 \mathrm{~h}$ (IL-6: $P=0.037$, TNF- $\alpha: P=0.037$ ). The protein of $\beta$-catenin in the nucleus was not affected by IH and gut microbiota from OSAS.

Conclusions Our study demonstrated that IH and gut microbiota of patients with OSAS activated HIF- $1 \alpha$ expression and STAT3 pathway in IMCE cells, with no influence on $\beta$-catenin pathway, which suggested that IH, STAT3 pathway, chronic inflammation, and intestinal microbiota dysbiosis may be involved in CRC carcinogenesis correlated with OSAS These findings must be interpreted cautiously and further research is necessary to clarify the causative steps in CRC development.
\end{abstract}

Keywords Colorectal cancer $\cdot$ Obstructive sleep apnea syndrome $\cdot$ Intermittent hypoxia $\cdot$ Intestinal microbiota

Bangmao Wang

mwang02@tmu.edu.cn

1 Department of Gastroenterology and Hepatology, Tianjin Medical University General Hospital, No.154, Anshan Road, Heping District, Tianjin, China

2 Department of Geriatrics, Tianjin Geriatrics Institute, Tianjin Medical University General Hospital, No.154, Anshan Road, Heping District, Tianjin, China

\section{Introduction}

Colorectal cancer (CRC) is very common worldwide, which lists third in morbidity and second in mortality overall worldwide [1], and the trend is still uprising in many countries, such as Russia, China, and Brazil. Twenty percent emergence of CRC could be referred to genetic background, such as hereditary non-polyposis colorectal cancer (HNPCC or Lynch syndrome), hamartomatous polyposis syndrome, and familial adenomatous polyposis (FAP), with characteristic of family history. The largest fraction of CRC cases is linked to 
environmental and nonhereditary events. Among them, chronic inflammation is a significant risk factor for CRC development [2], and some cytokines such as IL-6 and TNF- $\alpha$ play very important role in this process. The activations of Wnt/ $\beta$-catenin pathway and IL-6/STAT3 pathway have been proved key procedures in CRC carcinogenesis. The environment pathogenic factors of CRC are commonly about personal lifestyle, and the relevant research is useful for disease prevention. High fat diet, insufficient intake of dietary fiber, high consumption of red or processed meat, body fatness, alcohol drinks, gut microbiota disorder [3], and ulcerative colitis [4] have been proved to have the relationship with CRC. People with these characteristics usually have obesity problem and many metabolism abnormalities, and also together with sleep apnea problems. Sleep apnea is indeed prevalent among colorectal cancer patients [5].

Obstructive sleep apnea syndrome (OSAS), also very prevalent in modern society, is a kind of sleep breathing disorder, with repeated partial or complete upper airway collapse. OSAS is characterized by intermittent hypoxia $(\mathrm{IH})$, microarousal, and sleep fragmentation during sleep [6], affecting at least $2-4 \%$ of the adult population [7]. Many OSAS patients share the common risk factors with CRC patients: obesity body shape, often caused by unhealthy lifestyle. OSAS could induce multi-system disorders, and has been considered an independent risk factor for cardiovascular disease, cerebrovascular disease, and metabolic disease [8-16]. The patients with OSAS usually have elevated cancer burden [17-19]. In patients with lung cancer for example, OSAS is very prevalent [20,21]. Some studies also have shown that OSAS could increase the risk of developing colorectal cancer [22, 23]. A cohort study suggested that OSAS even may promote the CRC development independently beyond the obesity [24]. These studies have demonstrated the association between OSAS and $\mathrm{CRC}$, but the mechanism has not been investigated.

Intermittent hypoxia $(\mathrm{IH})$ is key characteristic of OSAS, and it could induce multiple organ impairment. Continuous hypoxia condition could promote colon cancer cell proliferation and invasion [25-27], but whether IH could induce the carcinogenesis of CRC is still not clear and lack of related research. Beside the direct hypoxia effect, IH could activate the hypoxia-induced factor (HIF) and NF- $\mathrm{BB}$, promoting the release of inflammatory factor [28], such as IL-6 and TNF- $\alpha$. Elevated levels of IL-6 [29] and TNF- $\alpha$ [30] have been observed in OSAS patients, which may exert effect on intestinal epithelial cells and induce the inflammation and carcinogenesis in the intestine. Hypoxia and HIFs could also influence both $\mathrm{Wnt} / \beta$-catenin and IL-6/STAT3 pathways. But whether these hypotheses work in CRC carcinogenesis needs further investigation.

The human large intestine contains the most microorganisms in the body, which play an important role in absorption, metabolism, and storage of ingested nutrients, with potentially profound effects on host physiology. Intestinal microbiota could also influence the inflammation level through interaction with immunocyte and producing short-chain fatty acid (SCFA) by fermentation. Microbiota dysbiosis has been proved to be associated with CRC [31]. Some specific bacteria, such as Bacteroides fragilis and Fusobacterium nucleatum, could impose effect on E-cadherin and activate $\mathrm{Wnt} / \beta$-catenin signaling by toxin or adhesin, promoting colorectal carcinogenesis $[32,33]$. These two kinds of pathogenic bacteria are both anaerobic bacteria, which may show more adaptation for the hypoxia microenvironment in OSAS patients compared with common intestinal bacteria. Some research has shown that OSAS could induce the intestinal microbiota dysbiosis [34], and microbiota dysbiosis correlation with OSAS could induce the inflammation $[35,36]$. Then, we could assume that the intestinal microbiota dysbiosis in OSAS patients may contain more pathogens or induce the inflammation in the intestine, which could induce the CRC carcinogenesis.

Therefore, we hypothesized that IH and intestinal microbiota dysbiosis in OSAS patients may have the ability to activate one or more $\mathrm{CRC}$ carcinogenesis pathways, and inflammation may be involved in this process. To validate our hypotheses, we exposed Immorto-Min colonic epithelial (IMCE) cells to $\mathrm{IH}$ and sterile fecal supernatant from OSAS to establish precancerous cell model, mimicking CRC premalignancy in OSAS patients, and the expressions of genes and inflammation cytokines associated with colorectal cancer, such as $\beta$ catenin, STAT3, HIF-1 $\alpha$, IL-6, TNF- $\alpha$, c-myc, and cyclinD1, were analyzed to evaluate the effect of IH and microbiota of OSAS on CRC development.

\section{Materials and methods}

\section{IMCE cell culture and IH exposure}

IMCE cell line was preserved in the laboratory of Gastroenterology and Hepatology department (Tianjin Medical University General Hospital), which was kindly provided by Professor Fang Yan from Vanderbilt University. IMCE cells were cultured in RMPI 1640 medium (Gibco, Invitrogen Corporation, NY, USA) supplemented with $10 \%$ FBS (Gibco, Invitrogen Corporation, NY, USA), 0.05\% interferon- $\gamma, 100 \mathrm{U} / \mathrm{ml}$ benzyl penicillin, and $100 \mu \mathrm{g} / \mathrm{ml}$ streptomycin under a circumstance of $33{ }^{\circ} \mathrm{C}$ with $5 \% \mathrm{CO} 2$, and passaged every 3-5 days. Before $\mathrm{IH}$ exposure, the cells were changed into starvation medium (RMPI 1640 medium mixed with $1 \%$ FBS, $100 \mathrm{U} / \mathrm{ml}$ benzyl penicillin, and $100 \mu \mathrm{g} / \mathrm{ml}$ streptomycin) for $12 \mathrm{~h}$. Then, cells were exposed in the experiment room, under intermittent hypoxic condition for 4,8 , or 12 $\mathrm{h}$, and parts of cells were preserved without IH treatment as the control group. IH exposure was in a plexiglas chamber, which 
was alternately flushed with a hypoxia gas mixture $(1.5 \% \mathrm{O} 2$, $5 \% \mathrm{CO} 2$, and balanced $\mathrm{N} 2$, hypoxia phase, $300 \mathrm{~s}$ ) or normoxia gas mixture $(21 \% \mathrm{O} 2,5 \% \mathrm{CO} 2$, and balanced $\mathrm{N} 2$, reoxygenation phase, $600 \mathrm{~s}$ ) controlled by a computed engine. This IH exposure system for cell experiments was set up earlier by the Department of Respiratory Medicine in Tianjin Medical University General Hospital [37], and it has been widely used for OSAS simulation [38-40]. Our research team has used this system to mimic OSAS impairment for hippocampal neurons [41], pancreatic $\beta$-cells [42], and liver cells [43].

\section{Cell incubation with feces fluid of OSAS patients}

Fresh feces were collected from 6 OSAS patients (O group) and 6 control healthy people (C group). In each group, $1 \mathrm{~g}$ of each sample was taken to mix together. The mixed feces were placed in sterile phosphate-buffered saline $(100 \mathrm{mg} / \mathrm{ml})$, homogenized, and centrifuged at $1000 \mathrm{rpm}$ for $1 \mathrm{~min}$, and the supernatant was collected as previously described $[44,45]$. Then, the fecal fluid was filtrated through a $40-\mu \mathrm{m}$ filter (BD Falcon) to remove big impurities. After that, a $0.2-\mu \mathrm{m}$ filter (Acrodisc syringe filter) was used to filter the bacteria in the fecal supernatant. Twelve hours before incubation, the cells were changed into starvation medium. Then, filtered fecal supernatant was added into cell culture medium (1:100) to incubate, under a circumstance of 37 ${ }^{\circ} \mathrm{C}$ for $12 \mathrm{~h}$. Then, the cells were treated under intermittent hypoxic condition for 4,8 , or $12 \mathrm{~h}$. The ways of fecal fluid preparation and incubation with intestinal cells were used earlier for research of adenocarcinoma caused by dysbiosis [44], and for the research of chronic constipation caused by dysbiosis [46], but fecal fluid in former experiment was not suitable for longtime incubation with cells because it was not sterile; here we improved the way.

\section{Real-time PCR analysis}

Total RNA was extracted by Trizol reagent (Applied Biosystems, USA), and cDNA reverse transcription was carried out using the TIANScript RT kit (TIANGEN, Inc. Beijing, China) according to the manufacturer's instructions. The oligonucleotide primers were synthesized in GENEWIZ (Suzhou, China). Relevant oligonucleotide primer sequences were shown in Table 1. All the primer sequences were validated in nucleotide BLAST (http://blast.ncbi.nlm.nih.gov/Blast.cgi). Real-time PCR was conducted to quantify the transcription of cytokines such as IL- 6 and TNF- $\alpha$, and the transcription of genes associated with colorectal cancer such as HIF- $1 \alpha$, $\beta$-catenin, STAT3, cyclinD1, and c-myc. Glyceraldehyde-3phosphate dehydrogenase (GAPDH), known as a housekeeping gene, was used as inner control to normalize the relative expression of targeted genes at mRNA level, which has been validated in some former researches [47-55]. ABI Prism 7000 real-time PCR system (Applied Biosystems, Carlsbad, CA) was
Table 1 Gene sequences of primers in the present study

\begin{tabular}{ll}
\hline Primers & Sequences \\
\hline GAPDH & $\begin{array}{l}\text { Forward: 5'-TGTGTCCGTCGTGGATCTGA-3' } \\
\text { Reverse: 5'-CCTGCTTCACCACCTTCTTGA-3' }\end{array}$ \\
HIF-1 $\alpha$ & $\begin{array}{l}\text { Forward: 5'-TGCCACTTCCCCACAATG-3' } \\
\text { Reverse: 5'-GTCCATCTGTGCCTTCATCTC-3' }\end{array}$ \\
IL-6 & Forward: 5'-CCAGTTGCCTTCTTGGGACT-3' \\
& Reverse: 5'-GGTCTGTTGGGAGTGGTATCC-3' \\
TNF- $\alpha$ & Forward: 5'-ACTCCAGGCGGTGCCTATG-3' \\
$\beta$-catenin & Reverse: 5'-GAGCGTGGTGGCCCT-3' \\
& Forward: 5'-GACACCTCCCAAGTCCTTTATG-3' \\
STAT3 & Reverse: 5'-AGCCCTAGTCATTGCATACTG-3' \\
& Forward: 5'-GGCACCTTGGATTGAGAGTC-3' \\
cyclinD1 & Reverse: 5'-AGGACATTGGACTCTTGCAG-3' \\
& Forward: 5'-TGACTGCCGAGAAGTTGTG-3' \\
c-myc & Reverse: 5'-TTGGAGAGGAAGTGTTCGATG-3' \\
& Forward: 5'-GCTGTTTGAAGGCTGGATTTC-3' \\
& Reverse: 5'-GATGAAATAGGGCTGTACGGAG-3' \\
\hline
\end{tabular}

used for real-time PCR procedure. SYBR Green PCR Master Mix (SYBR Select Master Mix, Applied biosystems, USA) was used for the RT-PCR detection. The procedure of PCR was constituted of 30 cycles followed by a period of $5 \mathrm{~min}$ at $72{ }^{\circ} \mathrm{C}$ for final extension. Within each cycle, the time period and temperature were $94^{\circ} \mathrm{C}$ for $30 \mathrm{~s}, 60^{\circ} \mathrm{C}$ for $30 \mathrm{~s}$, and $72{ }^{\circ} \mathrm{C}$ for $90 \mathrm{~s}$, respectively. The $2^{-\Delta \Delta \mathrm{Ct}}$ method was used to calculate relative mRNA expression.

\section{Western blot analysis}

After the IH treatment was finished, the cells were washed with phosphate-buffered saline (PBS) for two times, and then RIPA buffer was used before lysed. Nucleus and cytoplasmic protein extraction kit (Beyotime Biotechnology, Shanghai, China) was used to extract the protein from the cells. Proteinase inhibitor cocktail $(10 \mu \mathrm{l} / \mathrm{ml})$ (Sigma, St. Louis, MO, USA) and phosphatase inhibitor cocktail $(10 \mu \mathrm{l} / \mathrm{ml})$ (Sigma, St. Louis, MO, USA) were added separately. After that, the lysate was homogenized and centrifuged $(12,000 \mathrm{~g}, 4$ ${ }^{\circ} \mathrm{C}, 15 \mathrm{~min}$ ), and the supernatants were retained. The protein was separated by SDS-polyacrylamide gel electrophoresis, then transferred onto a PVDF membrane. Rabbit monoclonal antibodies (Abcam, USA), anti- $\beta$-catenin, anti-HIF- $1 \alpha$, antiIL-6, anti-p-STAT3, and anti-STAT3 were used correspondingly as primary antibodies. $\beta$-actin was used for total protein internal control and Histone $2 \mathrm{~A}$ for nucleus protein internal control. Goat anti-rabbit IgG conjugated with horseradish peroxidase antibodies (Abcam, USA) was used as secondary antibody. A chemiluminescence detection system (BIO-RAD, USA) was used to detect the membranes. Comparison between the intensity of targeted bands and the intensity of 
internal control band was achieved via an image processor program (Image J 1.51j8).

\section{Statistical analysis}

All statistical tests were performed with IBM SPSS Statistics 24. The data are described as mean \pm SD. Statistical analyses were performed by using Mann-Whitney test in comparison between only two groups. Data were compared between multi-groups by Kruskal-Wallis $H$ test. $P$ value less than 0.05 was considered statistically significant difference.

\section{Results}

\section{IH promoted HIF-1a expression}

IH could promote HIF-1 $\alpha$ expression both in mRNA level and protein level. We could observe that the mRNA level of HIF- $\alpha$ was significantly elevated after $8 \mathrm{~h}$ and $12 \mathrm{~h} \mathrm{IH}$ treatment compared with the control group (C group) $(P<0.05, F$ $=27.819)$, and increased during the longer IH exposure, but there were no statistically significant differences in the levels between 4 and $8 \mathrm{~h} \mathrm{IH}$ groups (Fig. 1). Similarly, the protein level of HIF- $\alpha$ was elevated after $12 \mathrm{~h}$ IH compared with the control group $(P<0.05, F=31.818)$, though with increasing trend, but there were no statistically significant differences in the levels between 8 and $12 \mathrm{~h}$ IH groups (Fig. 4b). These results showed that IH could activate HIF- $1 \alpha$ expression, and expression level correlated with length of IH exposure within $12 \mathrm{~h}$.

\section{IH may induce IMCE cell proliferation}

The mRNA level of c-myc was downregulated after $4 \mathrm{~h} \mathrm{IH} \mathrm{(} P$ $<0.05, F=25.7$ ), then increased during the longer IH exposure, but there were no statistically significant differences on the levels of $8 \mathrm{~h}$ and $12 \mathrm{~h} \mathrm{IH}$ groups compared with the control

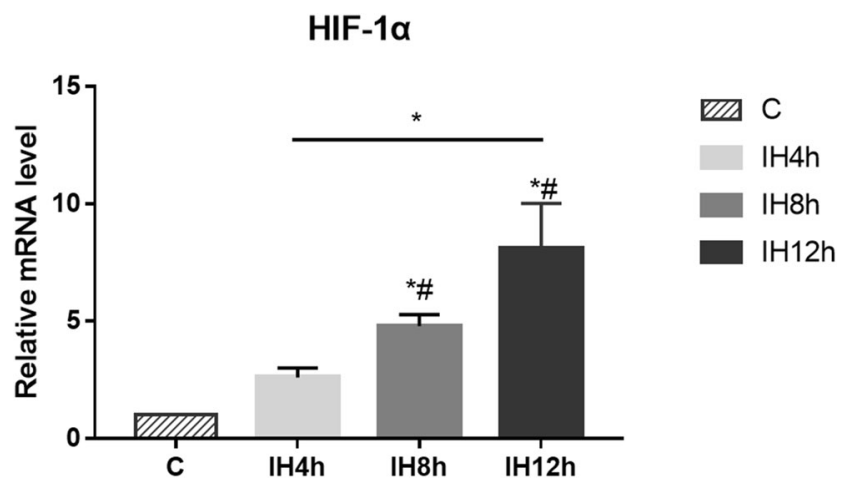

Fig. 1 The effect of IH on HIF-1 $\alpha$ expression in mRNA level. KruskalWallis $H$ test, Sig. $=0.015, * P<0.05, * \# P<0.05$ vs. $\mathrm{C}$ group, respectively group (Fig. 2a). The expression of cylinD1 in mRNA level increased after $12 \mathrm{~h} \mathrm{IH}$ compared with the control group $(P<$ $0.05, F=71.821$ ); though with increasing trend, the levels of $4 \mathrm{~h}$ and $8 \mathrm{~h}$ group had no statistically significance compared with the control group (Fig. 2b). These results suggested that IH could activate cyclinD1 expression, which indicate cell proliferation. Though we did not see c-myc expression increased statistically compared with the control group, the results still showed the increasing trend during IH exposure.

\section{IH could activate tumorigenesis pathway}

$\beta$-catenin was detected in mRNA level, and protein level in the nucleus to observe whether $\mathrm{Wnt} / \beta$-catenin pathway was activated, together with detecting STAT3 and p-STAT3 in the nucleus for IL-6/STAT3 pathway. TNF- $\alpha$ and IL-6 were detected to evaluate the inflammation induced by IH. In mRNA level, there were no statistically significant differences for TNF- $\alpha$ after $4 \mathrm{~h}, 8 \mathrm{~h}$, and $12 \mathrm{~h} \mathrm{IH}$ exposure compared with the control group (Fig. 3a), and IL-6 was elevated after $4 \mathrm{~h} \mathrm{IH}$ exposure, but fell back to initiate level after $8 \mathrm{~h}$ and $12 \mathrm{~h} \mathrm{IH}$ exposure $(P<0.05, F=22.058)$ (Fig. 3b). In protein level for IL-6, there were no statistically significant differences after 4 h, $8 \mathrm{~h}$, and $12 \mathrm{~h} \mathrm{IH}$ compared with the control group (Fig. 4d). Though we could see the expression of $\beta$-catenin in mRNA level was elevated after $12 \mathrm{~h} \mathrm{IH}$ compared with the control group ( $P<0.05, F=39.923)$ (Fig. 3d), no elevation for protein level in the nucleus was observed (Fig. $5 \mathrm{c}$ ). In another pathway, both mRNA $(P<0.05, F=172.351)$ (Fig. 3c) and protein level $(P<0.05, F=40.698)$ (Fig. 4 c) of STAT3 were significantly elevated after $12 \mathrm{~h} \mathrm{IH}$ compared with the control group. Also, we could observe that p-STAT3 transported to the nucleus was significantly elevated after $2 \mathrm{~h} \mathrm{IH}(P<0.05, F$ $=91.143$ ) (Fig. 5b). These results indicated that STAT3 pathway was activated in IH exposure, which may induce CRC tumorigenesis, but not through IL-6 activating.

\section{Gut microbiota of OSAS could activate tumorigenesis pathway}

At the mRNA level, we could see $\mathrm{O}$ group expressed similar amount mRNA of HIF- $1 \alpha$ with $\mathrm{C}$ group at most time point, only decreased at $0 \mathrm{~h}$ point compared with $\mathrm{C}$ group ( $P$ $<0.05, F=4.528$ ) (Fig. 6a). At the protein level, we could see that the IMCE cells of $\mathrm{O}$ group produced lower HIF-1 $\alpha$ in the normoxia environment $(0 \mathrm{~h}$ point, $P<0.05, F=$ 7.999) (Fig. 8b), but after IH exposure, O group IMCE cells produced more HIF- $1 \alpha$ at $4 \mathrm{~h}(P<0.05, F=0.131)$ and $12 \mathrm{~h}(P<0.05, F=1.252) \mathrm{IH}$ points, and at $8 \mathrm{~h} \mathrm{IH}$ point, $\mathrm{O}$ group's HIF-1 $\alpha$ also had increasing trend but without statistical significance (Fig. 8b). IL-6 was elevated at $4 \mathrm{~h}(P<$ $0.05, F=13.571)$ and $8 \mathrm{~h}(P<0.05, F=6.664) \mathrm{IH}$ points for mRNA level in O group (Fig. 6b), but for protein level, 
a

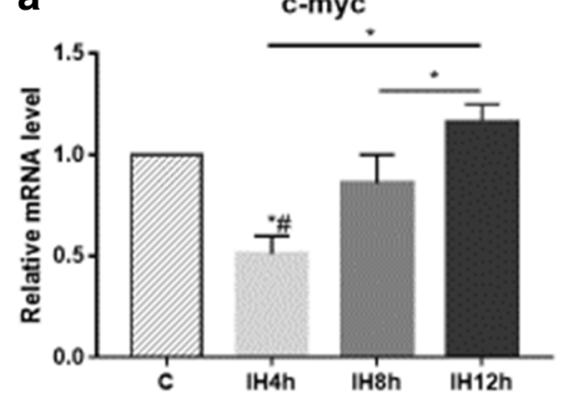

b

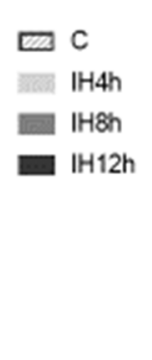

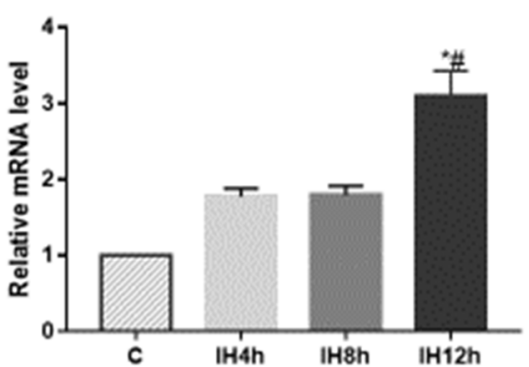

cyclinD1

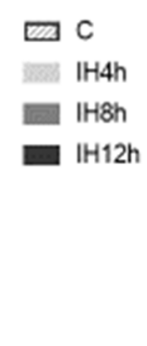

Fig. 2 The effect of IH on expression of genes related to the control of cell proliferation: c-myc (a), cyclinD1 (b), detected by real-time-PCR. a KruskalWallis $H$ test, Sig. $=0.015$. b Kruskal-Wallis $H$ test, Sig. $=0.023$. $* P<0.05, * \# P<0.05$ vs. C group, respectively

the elevation appeared at $12 \mathrm{~h}$ in $\mathrm{O}$ group $(P<0.05, F=$ 2.937) (Fig. 8c). TNF- $\alpha$ was elevated in $\mathrm{O}$ group at $4 \mathrm{~h}$ and $8 \mathrm{~h}$ points for mRNA level $(4 \mathrm{~h}: P<0.05, F=5.808 ; 8 \mathrm{~h}: P$ $<0.05, F=7.942$ ) (Fig. $6 c$ ). We could see that both IL-6 and TNF- $\alpha$ were elevated most in mRNA level for $4 \mathrm{~h} \mathrm{O}$ group, which indicated that the inflammation induced by OSAS patient's microbiota under IH condition was not proportional to IH duration. The expression of $\beta$-catenin in $\mathrm{O}$ group had no statistical significance with that in $\mathrm{C}$ group at each point both for mRNA level (Fig. 7b) and protein level in the nucleus (Fig. 9c). STAT3 was significantly elevated in $\mathrm{O}$ group at each time point for the mRNA level $(P<0.05$, 0 h: $F=5.851 ; 4$ h: $F=8.140 ; 8$ h: $F=13.795 ; 12$ h: $F=$ 12.544) (Fig. 7a) and protein level $(P<0.05,0 \mathrm{~h}: F=$ 5.325; 4 h: $F=7.566 ; 8$ h: $F=1.029 ; 12$ h: $F=2.444)$

a
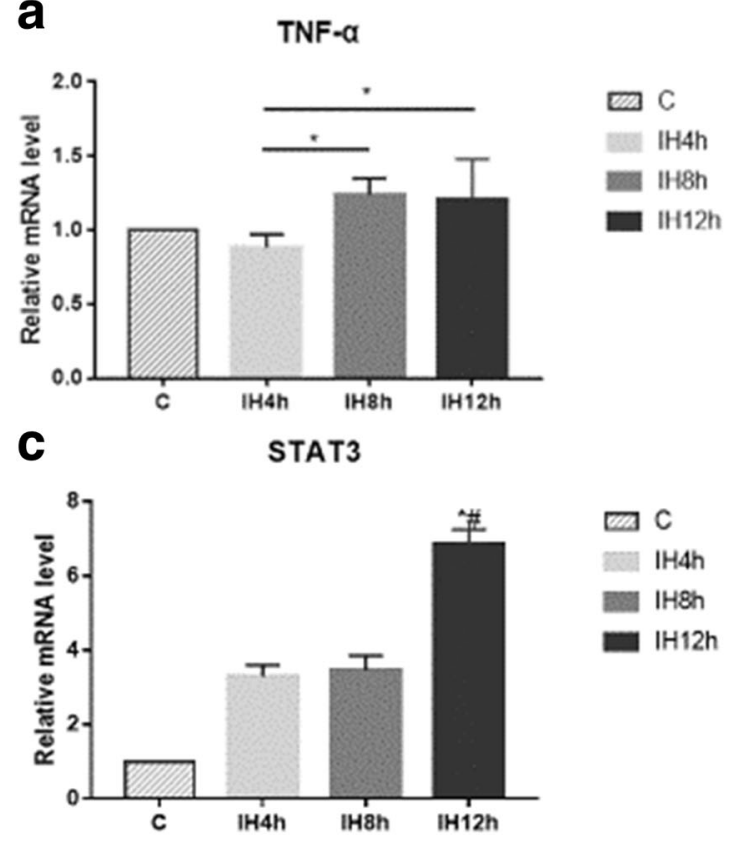

Fig. 3 The effect of IH on CRC tumorigenesis pathway, mRNA level of TNF- $\alpha(\mathbf{a})$, IL-6 (b), STAT3 (c), and $\beta$-catenin (d), detected by real-timePCR. a Kruskal-Wallis $H$ test, Sig. $=0.047$. b Kruskal-Wallis $H$ test, Sig.
(Fig. 8d). For p-STAT3 in the nucleus, O group had similar p-STAT3 level with $\mathrm{C}$ group at $0 \mathrm{~h}$ point, but after $\mathrm{IH}$ exposure, more p-STAT3 was detected in $\mathrm{O}$ group cell nucleus $(P<0.05,4$ h: $F=1.569 ; 8$ h: $F=13.130 ; 12$ h: $F=$ 9.730) (Fig. 9b). These results suggested that gut microbiota of OSAS patients could activate STAT3 pathway under IH condition, which may induce CRC tumorigenesis, and this procedure was not through IL-6 activating. We also could see the c-myc was elevated in $\mathrm{O}$ group at $4 \mathrm{~h}(P<0.05, F=$ 15.246) and $8 \mathrm{~h}(P<0.05, F=9.446) \mathrm{IH}$ point (Fig. $7 \mathrm{c})$, and cyclinD1 was elevated in $\mathrm{O}$ group at $4 \mathrm{~h} \mathrm{IH}$ point $(P<$ $0.05, F=12.714$ ) (Fig. $7 \mathrm{~d}$ ), which indicated that gut microbiota of OSAS patients may activate the cell proliferation under $4 \mathrm{~h} \mathrm{IH}$ conditions, but not for excessive long or short IH conditions.

\section{b}

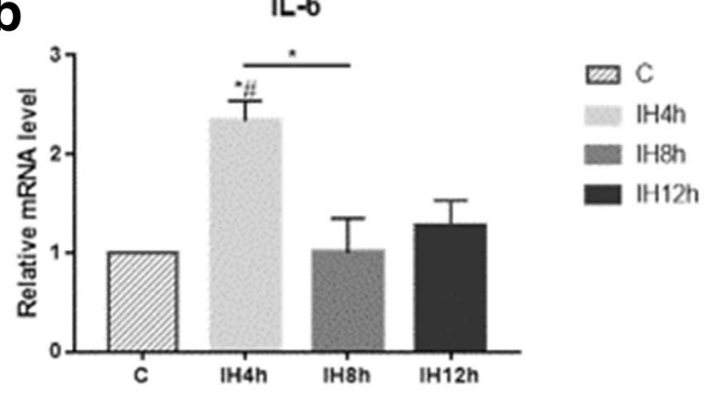

d

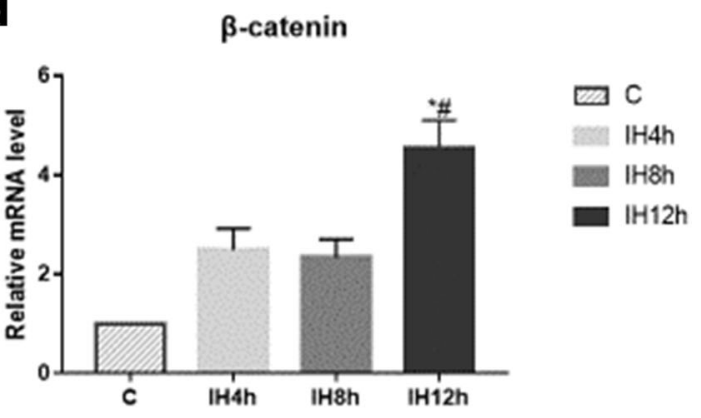

$=0.041$. c Kruskal-Wallis $H$ test, Sig. $=0.023$. d Kruskal-Wallis $H$ test, Sig. $=0.022 . * P<0.05, * \# P<0.05$ vs. C group, respectively 
a

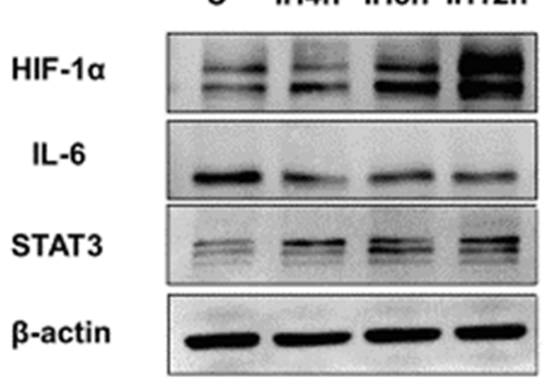

C

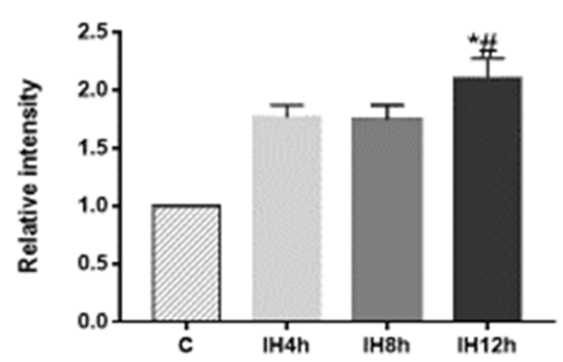

Fig. 4 The effect of IH on CRC tumorigenesis pathway, detected by Western blot analysis (a): the protein level of HIF-1 $\alpha(\mathbf{b})$, STAT3 (c), and IL-6 (d). b Kruskal-Wallis $H$ test, Sig. $=0.027$. c Kruskal-Wallis $H$

\section{Discussion}

MCE cell line is phenotypically normal, but it has proven to be susceptible to transformation, so it is a very suitable model system available for studying malignant progression in colon cancer [56]. In our study, we exposed IMCE cells to IH for 4, b

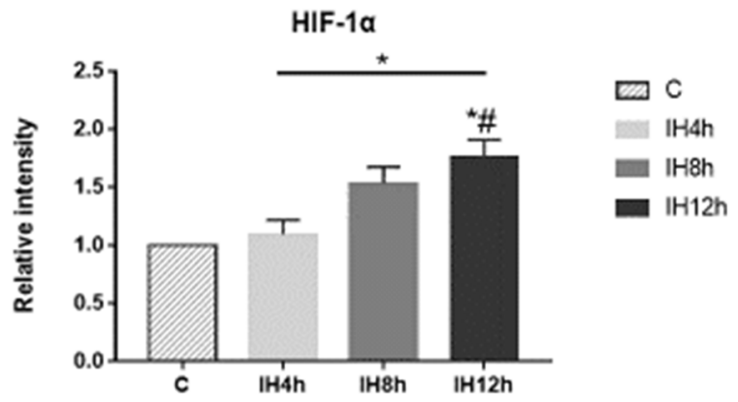

d

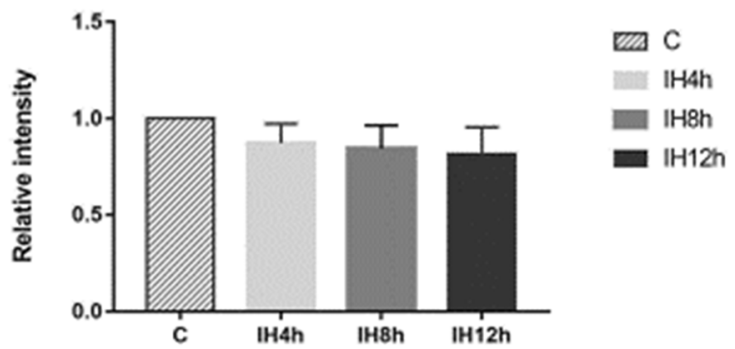

test, Sig. $=0.023$. d Kruskal-Wallis $H$ test, Sig. $=0.55$. $* P<0.05$, $* \# P<$ 0.05 vs. C group, respectively

8 , and $12 \mathrm{~h}$ in the first part. It was observed that the expression of HIF-1 $\alpha$, cyclinD1, and STAT3 was upregulated in the IH group, and p-STAT3 moving into the nucleus was also elevated in the IH group, and both of them getting to the most after $12 \mathrm{~h} \mathrm{IH}$; the mRNA of $\beta$-catenin was elevated, but the $\beta$-catenin protein moving into the nucleus showed no a

\section{p-STAT3 (nucleus) \\ $\beta$-catenin (nucleus)}

Histone 2A

\section{IH4h $\mathrm{IH} 8 \mathrm{~h} \mathrm{IH} 12 \mathrm{~h}$}

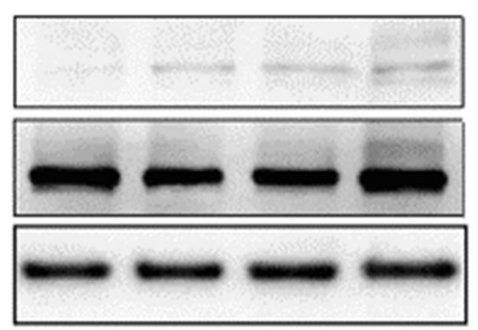

b
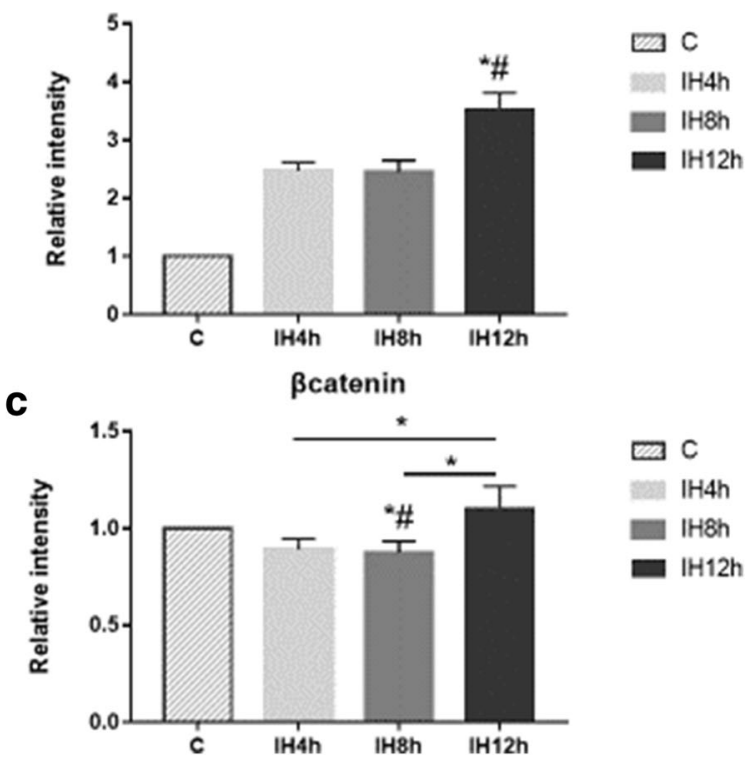

Fig. 5 The effect of IH on CRC tumorigenesis pathway, detected by Western blot analysis (a): the protein level of p-STAT3 (b), $\beta$-catenin (c), in IMCE cell nucleus. b Kruskal-Wallis $H$ test, Sig. $=0.023$. c Kruskal-Wallis $H$ test, Sig. $=0.034 . * P<0.05, * \# P<0.05$ vs. C group, respectively 
a

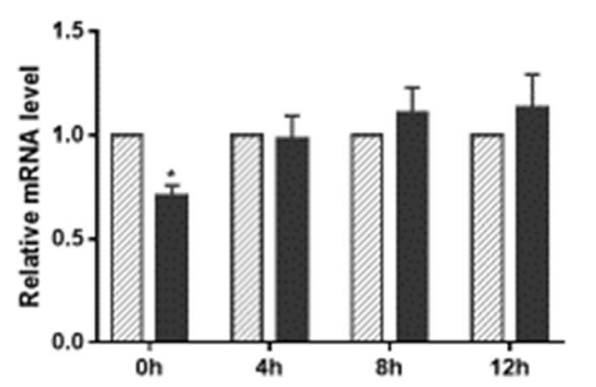

C

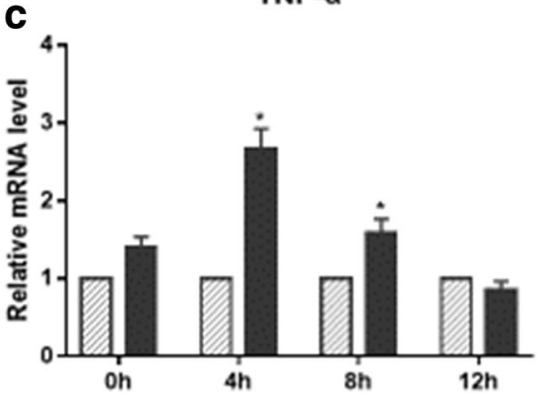

Fig. 6 The effect of OSAS fecal content on CRC tumorigenesis pathway under IH condition, mRNA level of HIF- $1 \alpha(\mathbf{a})$, IL-6 (b), and TNF- $\alpha(\mathbf{c})$, detected by real-time-PCR. a Mann-Whitney test, 0 h group: $P=0.037$. b

significant change under IH. IL- 6 and TNF- $\alpha$ also showed no significant change under IH. Then, we combined the IH exposure and fecal fluid incubation together to treat IMCE cells. Data showed that HIF-1 $\alpha$, STAT3, and p-STAT3 in the nucleus were elevated in the OSAS group compared with the

a

STAT3

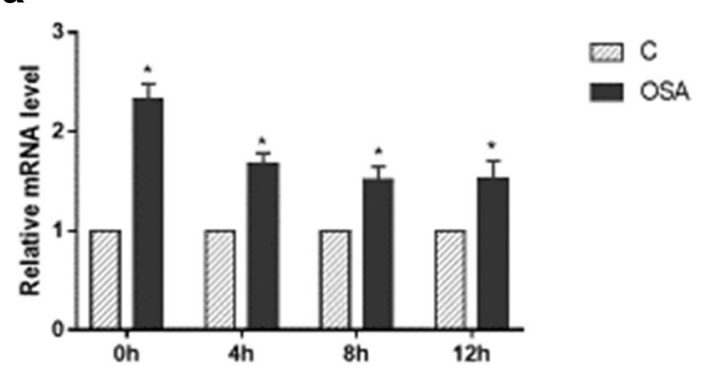

C

c-myc

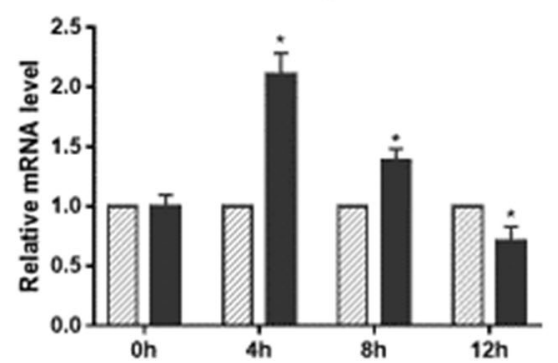

Fig. 7 The effect of OSAS fecal content on CRC tumorigenesis pathway under IH condition, mRNA level of STAT3 (a), $\beta$-catenin (b), c-myc (c), and cyclinD1 (d), detected by real-time-PCR. a Mann-Whitney test, $0 \mathrm{~h}$ group: $P=0.037,4$ hroup: $P=0.046,8$ hroup: $P=0.037,12 \mathrm{~h}$ group: b IL-6

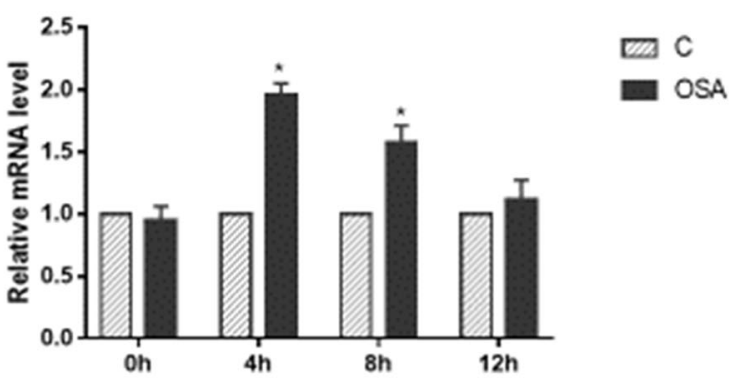

4 h group: Mann-Whitney test, $P=0.037,8$ h group: $P=0.037$. $\mathrm{c} 0 \mathrm{~h}$ group: Mann-Whitney test, 4 h group: $P=0.037,8$ h group: $P=0.037$. $* P$ $<0.05$ vs. C group of each IH time point

healthy control group. Expressions of IL- 6 and TNF- $\alpha$ were elevated in the OSAS group for mRNA level at $4 \mathrm{~h}$ and $8 \mathrm{~h}$ IH exposure, though without significant change for protein level. The expression of $\beta$-catenin in mRNA level and $\beta$ catenin protein moving into the nucleus also showed no

b

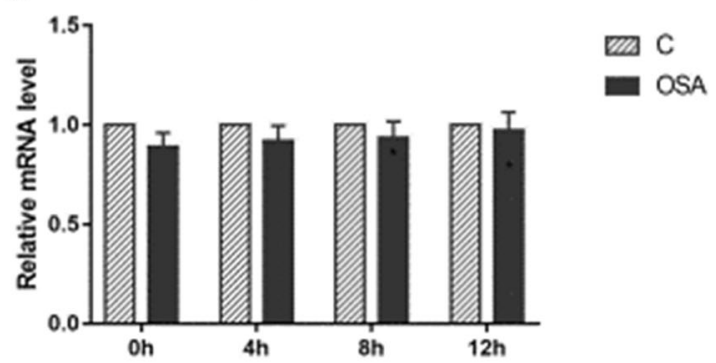

d cyclinD1

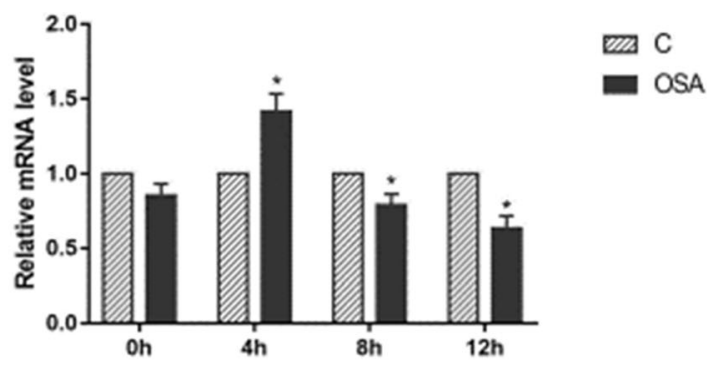

$P=0.037$. c Mann-Whitney test, 4 h group: $P=0.037,8$ h group: $P=$ $0.037,12$ h group: $P=0.037$. d Mann-Whitney test, 4 h group: $P=0.046$, 8 h group: $P=0.037,12$ h group: $P=0.037$. $* P<0.05$ vs. $\mathrm{C}$ group of each IH time point 
a

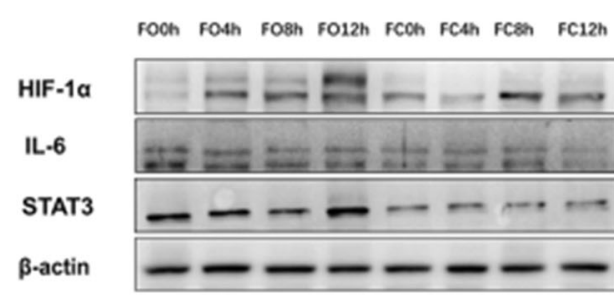

C

IL-6

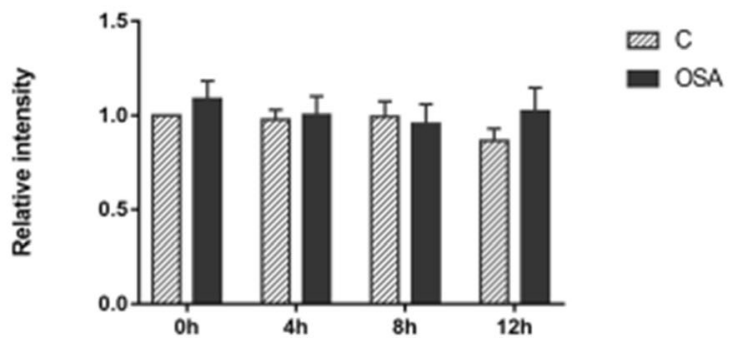

Fig. 8 The effect of OSAS fecal content on CRC tumorigenesis pathway under IH condition, detected by Western blot analysis (a): the protein level HIF-1 $\alpha$ (b), IL-6 (c), STAT3 (d). b Mann-Whitney test, $0 \mathrm{~h}$ group:

significant changes between the two groups. The expressions of cyclinD1 and c-myc were upregulated in the OSAS group significantly at $4 \mathrm{~h} \mathrm{IH}$ exposure, but downregulated in the OSAS group at $12 \mathrm{~h} \mathrm{IH}$ exposure.

Cancer cells proliferate quickly and consume much oxygen, so malignant tumors usually contain hypoxic regions, which is the characteristic of tumor microenvironment. Tumor cells develop corresponding mechanisms for hypoxia

a

FOOh FO4h FO8h FO12h FCOh FC4h FC8h FC12h

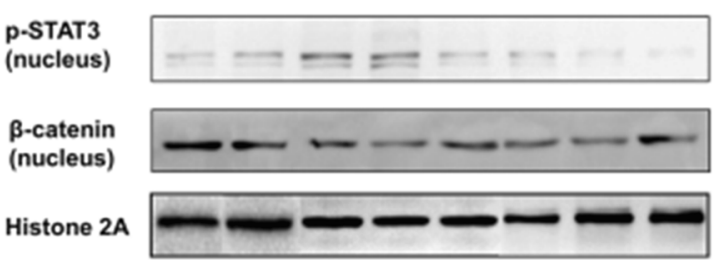

Fig. 9 The effect of OSAS fecal content on CRC tumorigenesis pathway under IH condition, detected by Western blot analysis (a): the protein level p-STAT3 (b), $\beta$-catenin (c) in IMCE cell nucleus. b Mann-
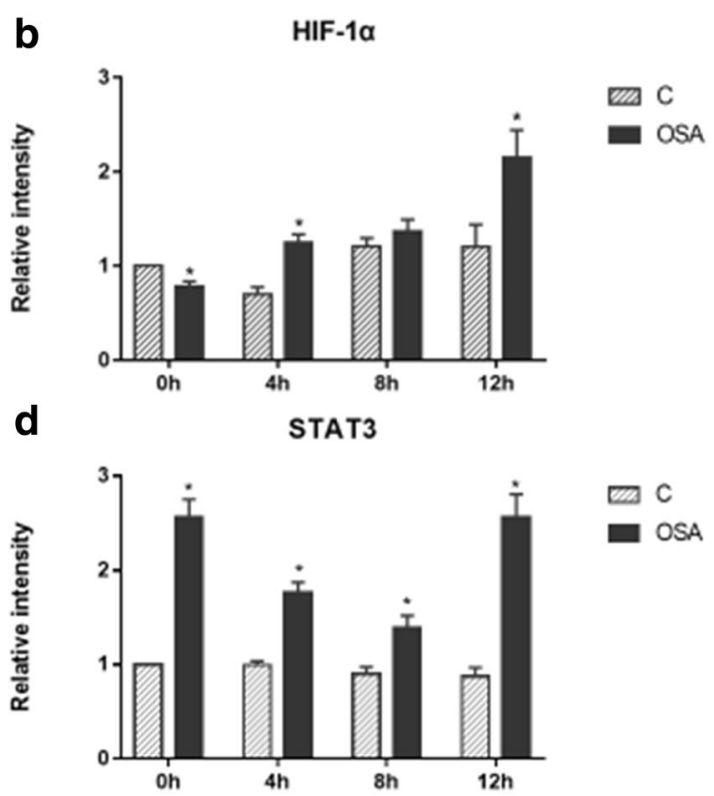

$P=0.046,4$ hroup: $P=0.046,12$ h group: $P=0.046$. d Mann-Whitney, 0 h group: $P=0.037,4$ h group: $P=0.046,8$ h group: $P=0.049,12 \mathrm{~h}$ group: $P=0.037$. $* P<0.05$ vs. $\mathrm{C}$ group of each $\mathrm{IH}$ time point

environment adaptation. HIFs are activated in hypoxia conditions, regulating the expression of many genes that code for proteins involved in angiogenesis [57], glucose metabolism, and cell proliferation [58], which play important role for hypoxia tolerance. HIF- $1 \alpha$ is the most important one among HIFs. Overexpression of HIF- $1 \alpha$ in tumor cells is closely connected with increased resistance to radio- and chemotherapies, increased risk of metastasis, more aggressive

b

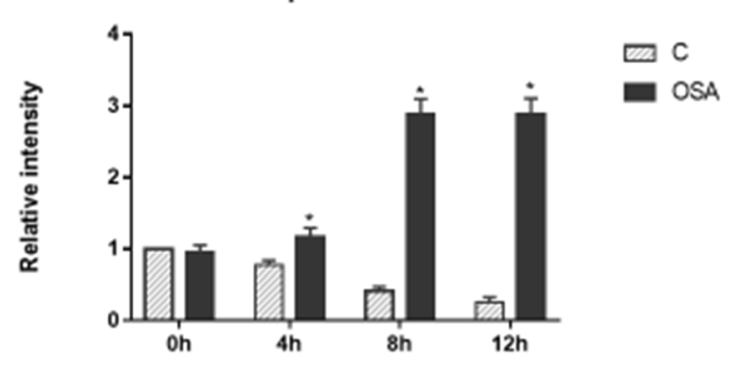

C

$\beta$-catenin

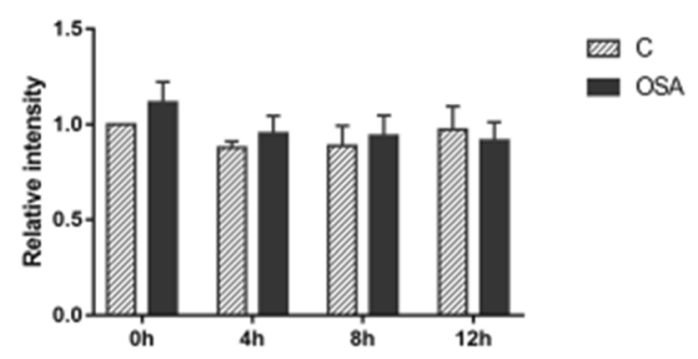

Whitney test, 4 h group: $P=0.049,8$ h group: $P=0.046,12$ h group: $P$ $=0.046 . * P<0.05$ vs. $\mathrm{C}$ group of each IH time point 
phenotype, and strengthened immune suppression [59]. HIFs are also involved in COX2/mPGES-1/PGE2, WNT, and STAT3 signaling pathways correlating with CRC carcinogenesis $[25,60,61]$, and implicated in CRC development and metastasis [62-67]. But the conclusions above were acquired under continuous hypoxia condition.

Chronic IH is the key pathogenesis of OSAS damage. Different from continuous hypoxia, IH is in cycling reoxygenation, and reactive oxygen species could be generated in this progress, which is more similar with ischemia-reperfusion process, so OSAS could be regarded as an oxidative stress disorder [68]. The shift frequency of hypoxia and reoxygenation in OSAS patients could be very high, up to more than 5100 times per hour [69], and blood oxygen saturation may be changed violently, even down to $20 \%$. Multiple organs in OSAS patients would show damage in function and tissue, such as the cardiovascular, brain, liver, pancreas, and kidney. OSAS could aggravate the hypoxia in tissues. But seldom research focused on whether OSAS would promote CRC carcinogenesis. In HCT 116 cells, HIF- $1 \alpha$ could be activated in a hypoxia dose-dependent manner under IH condition [70], but whether the pathway correlating with CRC carcinogenesis could be activated under chronic IH condition is still not clear. Our data showed that IH could promote p-STAT3 elevated in the nucleus, and mRNA expression of cyclinD1 also increased at the same time as its downstream target gene, suggesting that STAT3 may be activated under IH condition.

Beside genetic heredity, $\mathrm{CRC}$ could be divided into sporadic $\mathrm{CRC}$ and colitis-associated cancer (CAC), according to the molecular mechanism by which cancer was triggered and promoted. For sporadic CRC, classical "normal mucosa-adenoma-carcinoma" sequence has been considered to be the core mechanism, and $\mathrm{Wnt} / \beta$-catenin pathway plays an important role. Once activated, $\beta$-catenin would move into the nucleus, regulating its target gene such as cylinD1, c-myc, and MMP-7 which control the cell proliferation [71]. But for CAC, chronic inflammation is a crucial cancer promoter. Two key genes in the inflammatory process, cyclooxygenase-2 (COX-2) and nuclear factor kappaB (NF-kappaB), provide a mechanistic link between inflammation and cancer, while some cytokines, such as TNF- $\alpha$ and IL-6-induced signaling, have been recently shown to promote tumor growth in experimental models of colitis-associated cancer [72]. IL-6 could activate STAT3, which regulates the transcription of regulators of cellular proliferation (cyclinD1, proliferating cell nuclear antigen), survival (BCL-xL, surviving), and angiogenesis (VEGF) [73]. The activation of STAT3 signal pathway has been proved to be key in the CAC carcinogenesis process [73]. How about the mechanism of CRC carcinogenesis correlated with OSAS patients is still unknown to date. Our data showed that STAT3 pathway may be involved in this process. Because STAT3 mediates signaling from multiple inflammation cytokines, not only IL6, but also IL-11, IL-21, and IL-22, all of which play roles in
CRC development [74-80], so the activated STAT3 suggested that chronic inflammation may be involved in this process.

At present, it has been proved that hypoxia and HIFs could influence both $\mathrm{Wnt} / \beta$-catenin and IL-6/STAT3 pathways. HIF- 1 could activate and maintain the $\mathrm{Wnt} / \beta$-catenin pathway [81]. In HCT 116 cells, Wnt/ $\beta$-catenin pathway and cell proliferation are inhibited after HIF-1 $\alpha$ was blocked [82]; hypoxia could downregulate the APC expression in mRNA and protein level through HIF-1 $\alpha$-dependent mechanism [83]. HIF and p-STAT3 are upregulated in mice and human colon cancer cells, and HIF could promote colon cancer cell proliferation by activating JAK-STAT3 pathway [84]. HIF- $1 \alpha$ knockdown leads a significant decrease in the expression levels of STAT3 in human colon cells [85]. But the conclusions above were under continuous hypoxia condition and from cancer cells, how about the effect of chronic IH on colon premalignant cells is still unknown. Our results showed that IH could upregulate the expression of $\beta$-catenin mRNA, but we did not observe the increase of $\beta$-catenin protein in IMCE cell nucleus, and this indicated that $\mathrm{Wnt} / \beta$-catenin pathway was not activated indeed in our model. Restricted to experiment conditions, we could not test the effect of longer IH duration on $\beta$-catenin. IH could elevate the expression of STAT3 and promote p-STAT3 protein entering to the nucleus, which indicated that STAT3 pathway could be activated by IH. But curiously this STAT3 activation seemed not to be through IL- 6 in this process, because we did not see the elevation of IL-6 protein during IH exposure.

Many researches have shown that chronic IH could mimic the OSAS pathogenic process. But only IH itself may not be perfectly suitable for intestine research, because intestinal epithelium is inconstant contact with intestinal microbiota in vivo. It has been proved that the function and disease of intestine are affected by microbiota and their metabolic products. Some research has indicated that intestinal microbiota dysbiosis was induced in OSAS patients $[34,86]$ and OSAS animal models [87], and the similar situation even occurred in oral [88] and lung [89]. This change may play crucial role in pathogenesis process of OSAS-related hypertension [90, 91]. The changed intestinal microbiota by chronic IH could not be reversed even after normoxic recovery [92]. Those experiments above suggested that intestinal microbiota dysbiosis plays important role in OSAS pathogenic process, so it is not perfectly suitable that using IH only to mimic OSAS for intestine research without microbiota.

The microbiota dysbiosis in OSAS patients may correlate to sleep disorders and metabolic comorbidities. OSAS patients with Prevotella enterotype would exhibit worse sleep disruption [93]. Compared with common people, short-chain fatty acid (SCFA)-producing bacteria was decreased in OSAS patients, accompanied by increased pathogens and elevated levels of IL-6 and homocysteine. Stratification analysis revealed that the Ruminococcus enterotype posed the highest 
risk for patients with OSAS [34]. Research from real-life patients showed that gut microbiota dysbiosis and decreased SCFA in vivo significantly correlated with CRC $[94,95]$, so we could hypothesize that gut microbiota dysbiosis and SCFA decrease may be involved in the process of CRC carcinogenesis in OSAS patients. In mouse model, IH exposure could induce higher abundance of Firmicutes and a smaller abundance of Bacteroidetes and Proteobacteria phyla; at the level of dominant microbiota families and genera, Prevotella, Paraprevotella, Desulfovibrio, and Lachnospiraceae increased, whereas Bacteroides, Odoribacter, Turicibacter, Peptococcaceae, and Erysipelotrichaceae decreased in the feces [87]. The co-occurrence of Prevotella and Desulfovibrio suggests a mucin-degrading niche [53], because the sulfate which liberated during Prevotella-mediated mucin degradation could back inhibit this process, but Desulfovibrio could remove the sulfate $[96,97]$. The lack of mucin on the epithelial layer of the intestine could potentially lead to a significant alteration in intestinal permeability [87]. The enriched bacteria Desulfovibrio reduces sulfate in order to produce hydrogen sulfide (H2S), which has been reported as a possible contributing risk factor of colorectal cancer $[98,99]$. It has been proved that $\mathrm{IH}$ can directly impair cellular function and increase epithelium permeability [100], and translocation of nonpathogenic bacteria via the transcellular routes would increase under hypoxia [101]. Failure of intestinal epithelium barrier would lead to chronic inflammation [102]. Plasma IL- 6 and TNF- $\alpha$ have been proved to increase in patients with OSA [30, 103-107], and this increase of inflammation cytokines was even not improved by CPAP therapy [103, 108, 109], suggesting the inflammation seems not coming from IH only, which may be partially attributed to gut microbiota dysbiosis and destruction of intestinal epithelium barrier.

Our study showed that both $\mathrm{IH}$ and gut microbiota from OSAS patients could promote p-STAT3 entering to the nucleus, but we observed no change for $\beta$-catenin pathway in this process. It has been proved that gut microbiota dysbiosis of OSAS patients could induce inflammation, but we only observed elevation of inflammation cytokines for mRNA level in our model, which suggests that our cell model is far from perfect.

Our study had many limitations. We did not test the cell proliferation after IH exposure in this study, just tested the genes related to proliferation. Restricted to experiment conditions, it was not accurate for temperature modulation in $\mathrm{IH}$ exposure chamber, so the cells were not in good growth conditions during $\mathrm{IH}$ exposure, and this would lead to cell viability decrease or even cell death after longtime IH exposure. The outcome would be affected more when IH duration was longer, so we had to restrict IH duration to $12 \mathrm{~h}$ at most. Cell proliferation test, such as MTT test, may be meaningless in this condition. The amount of fecal sample was not sufficient enough, so we did not test the composition of feces microbiota in this study. Though we found STAT3 activated, but the pathway upstream is still not clear. Our IH parameters were performed according to previous teamwork $[42,43]$, and it was the first time used for intestine cells. We did not try any other IH parameters, or the outcome may be different. Conclusions of cell research still need further validations in animal models and clinical researches. So, our findings are very limited, and there is still very long distance from this conclusion to clarify CRC carcinogenesis associated with OSAS.

\section{Conclusion}

In summary, our data demonstrated that IH could activate the expression of HIF- $1 \alpha$, elevate the level of p-STAT3 in the nucleus, and promote the expression of cylinD1 in IMCE cells. Gut microbiota of OSAS patients could increase the expression of STAT3 and elevate the level of p-STAT3 in the nucleus under $\mathrm{IH}$, and promote the expression of IL- 6 , and TNF- $\alpha$ in mRNA level under IH less than $8 \mathrm{~h}$. Though elevated in mRNA level, $\beta$ catenin protein level in the nucleus was not affected by IH treatment and feces from OSAS patients. This suggested that $\mathrm{IH}$, STAT3 pathway, chronic inflammation, and intestinal microbiota dysbiosis may be involved in CRC carcinogenesis correlated with OSAS. But this conclusion is very limited, still long distance to clarify the CRC development.

Funding This study was funded by the National Natural Science Foundation Committee of China in the form of National Natural Science Foundation of China funding (No. 81970477). The sponsor had no role in the design or conduct of this research.

\section{Compliance with ethical standards}

Conflict of interest The authors declare that they have no conflict of interest.

Ethical approval All procedures performed in studies involving human participants were in accordance with the ethical standards of the institutional and/or national research committee and with the 1964 Helsinki declaration and its later amendments or comparable ethical standards.

Informed consent Informed consent was obtained from all individual participants included in the study.

Open Access This article is licensed under a Creative Commons Attribution 4.0 International License, which permits use, sharing, adaptation, distribution and reproduction in any medium or format, as long as you give appropriate credit to the original author(s) and the source, provide a link to the Creative Commons licence, and indicate if changes were made. The images or other third party material in this article are included in the article's Creative Commons licence, unless indicated otherwise in a credit line to the material. If material is not included in the article's Creative Commons licence and your intended use is not permitted by statutory regulation or exceeds the permitted use, you will need to obtain permission directly from the copyright holder. To view a copy of this licence, visit http://creativecommons.org/licenses/by/4.0/. 


\section{References}

1. Bray F, Ferlay J, Soerjomataram I, Siegel RL, Torre LA, Jemal A (2018) Global cancer statistics 2018: GLOBOCAN estimates of incidence and mortality worldwide for 36 cancers in 185 countries. CA Cancer J Clin 68(6):394-424

2. Feagins LA, Souza RF, Spechler SJ (2009) Carcinogenesis in IBD: potential targets for the prevention of colorectal cancer. Nat Rev Gastroenterol Hepatol 6(5):297-305. https://doi.org/10. 1038/nrgastro.2009.44

3. Song M, Chan AT, Sun J (2019) Influence of the Gut microbiome, diet, and environment on risk of colorectal cancer. Gastroenterology.

4. Desai D, Shah S, Deshmukh A et al (2015) Colorectal cancers in ulcerative colitis from a low-prevalence area for colon cancer. World J Gastroenterol 21(12):3644-3649

5. Claesson M, Fagerlund MJ, Haapamaki M et al (2006) Sleep apnea is prevalent among patients scheduled for surgery of colorectal cancer. Eur J Surg Oncol 42(9):s148

6. Lévy P, Tamisier R, Minville C, Launois S, Pépin JL (2011) Sleep apnoea syndrome in 2011: current concepts and future directions. Eur Respir Rev 20(121):134-146

7. Punjabi NM (2008) The epidemiology of adult obstructive sleep apnea. Proc Am Thorac Soc 5(2):136-143

8. Jean-Louis G, Zizi F, Clark LT, Brown CD, McFarlane SI (2008) Obstructive sleep apnea and cardiovascular disease: role of the metabolic syndrome and its components. J Clin Sleep Med 4(3):261-272

9. Durgan DJ, Bryan RM (2012) Cerebrovascular consequences of obstructive sleep apnea. J Am Heart Assoc 1(4):e000091

10. Hung J, Whitford EG, Parsons RW, Hillman DR (1990) Association of sleep apnoea with myocardial infarction in men. Lancet. 336(8710):261-264

11. Yaggi HK, Concato J, Kernan WN, Lichtman JH, Brass LM, Mohsenin V (2005) Obstructive sleep apnea as a risk factor for stroke and death. N Engl J Med 353(19):2034-2341

12. Pedrosa RP, Drager LF, Gonzaga CC et al (2011) Obstructive sleep apnea: the most common secondary cause of hypertension associated with resistant hypertension. Hypertension. 58(5):811-817

13. Tasali E, Mokhlesi B, Van Cauter E (2008) Obstructive sleep apnea and type 2 diabetes: interacting epidemics. Chest. 133(2): 496-506

14. Chen YH, Keller JK, Kang JH, Hsieh HJ, Lin HC (2013) Obstructive sleep apnea and the subsequent risk of depressive disorder: a population-based follow-up study. J Clin Sleep Med 9(5):417-423

15. Campos-Rodriguez F, Martinez-Garcia MA, Martinez $\mathrm{M}$ et al (2013) Association between obstructive sleep apnea and cancer incidence in a large multicenter Spanish cohort. Am J Respir Crit Care Med 187(1):99-105

16. Vgontzas AN, Bixler EO, Chrousos GP (2005) Sleep apnea is a manifestation of the metabolic syndrome. Sleep Med Rev 9(3):211-224

17. Sillah A, Watson NF, Schwartz SM, Gozal D, Phipps AI (2018) Sleep apnea and subsequent cancer incidence. Cancer Causes Control 29(10):987-994

18. Brenner R, Kivity S, Peker M et al (2019) Increased risk for cancer in young patients with severe obstructive sleep apnea. Respiration. 97(1):15-23

19. Martínez-García MÁ, Campos-Rodriguez F, Barbé F (2016) Cancer and OSA: current evidence from human studies. Chest. 150(2):451-463

20. Pérez-Warnisher MT, Cabezas E, Troncoso MF et al (2019) Sleep disordered breathing and nocturnal hypoxemia are very prevalent in a lung cancer screening population and may condition lung cancer screening findings: results of the prospective Sleep Apnea In Lung Cancer Screening (SAILS) study. Sleep Med 54:181-186
21. Cabezas E, Pérez-Warnisher MT, Troncoso MF et al (2019) Sleep disordered breathing is highly prevalent in patients with lung cancer: results of the sleep apnea in lung cancer study. Respiration. 97(2): 119-124

22. Brenner R, Kivity S, Peker M et al (2018) Increased risk for cancer in young patients with severe obstructive sleep apnea. Respiration.:1-9

23. Zhang X, Giovannucci EL, Wu K et al (2013) Associations of self-reported sleep duration and snoring with colorectal cancer risk in men and women. Sleep. 36(5):681-688

24. Lee S, Kim BG, Kim JW et al (2017) Obstructive sleep apnea is associated with an increased risk of colorectal neoplasia. Gastrointest Endosc 85(3):568-573.e1

25. Li H, Rokavec M, Jiang L, Horst D, Hermeking H (2017) Antagonistic effects of p53 and HIF1A on microRNA-34a regulation of PPP1R11 and STAT3 and hypoxia-induced epithelial to mesenchymal transition in colorectal cancer cells. Gastroenterology 153(2):505-520

26. Nagaraju GP, Bramhachari PV, Raghu G, El-Rayes BF (2015) Hypoxia inducible factor- $1 \alpha$ : its role in colorectal carcinogenesis and metastasis. Cancer Lett 366(1):11-18

27. Yu S, Zhou R, Yang T et al (2019) Hypoxia promotes colorectal cancer cell migration and invasion in a SIRT1-dependent manner. Cancer Cell Int 19:116

28. Ryan S, Taylor CT, McNicholas WT (2005) Selective activation of inflammatory pathways by intermittent hypoxia in obstructive sleep apnea syndrome. Circulation 112(17):2660-2667. https:// doi.org/10.1161/CIRCULATIONAHA.105.556746

29. Yokoe T, Minoguchi K, Matsuo H et al (2003) Elevated levels of C-reactive protein and interleukin-6 in patients with obstructive sleep apnea syndrome are decreased by nasal continuous positive airway pressure. Circulation 107(8):1129-1134. https://doi.org/ 10.1161/01.cir.0000052627.99976.18

30. Kataoka T, Enomoto F, Kim R et al (2004) The effect of surgical treatment of obstructive sleep apnea syndrome on the plasma TNF-alpha levels. Tohoku J Exp Med 204(4):267-272. https:// doi.org/10.1620/tjem.204.267

31. Abreu MT, Peek RM (2014) Gastrointestinal malignancy and the microbiome. Gastroenterology 146(6):1534-1546.e3. https://doi. org/10.1053/j.gastro.2014.01.001

32. Sears CL, Geis AL, Housseau F (2014) Bacteroides fragilis subverts mucosal biology: from symbiont to colon carcinogenesis. J Clin Invest 124(10):4166-4172. https://doi.org/10.1172/JCI72334

33. Rubinstein MR, Wang X, Liu W et al (2013) Fusobacterium nucleatum promotes colorectal carcinogenesis by modulating Ecadherin/ $\beta$-catenin signaling via its FadA adhesin. Cell Host Microbe 14(2):195-206. https://doi.org/10.1016/j.chom.2013.07.012

34. Ko CY, Liu QQ, Su HZ et al (2019) Gut microbiota in obstructive sleep apnea-hypopnea syndrome: disease-related dysbiosis and metabolic comorbidities. Clin Sci (Lond) 133(7):905-917

35. Poroyko VA, Carreras A, Khalyfa A et al (2016) Chronic sleep disruption alters gut microbiota, induces systemic and adipose tissue inflammation and insulin resistance in mice. Sci Rep 6: 35405. https://doi.org/10.1038/srep35405

36. Kheirandish-Gozal L, Peris E, Wang Y et al (2014) Lipopolysaccharide-binding protein plasma levels in children: effects of obstructive sleep apnea and obesity. J Clin Endocrinol Metab 99(2):656-663. https://doi.org/10.1210/jc.2013-3327

37. Jing F, Baoyuan C, Meinan G et al (2006) A noveI system for the simulation of various intermittent hypoxia modes. J Tianjin Med Univ 12(4):509-512

38. Liu ZK, Chen BY, Feng J et al (2011) The effect of intermittent hypoxia with different degrees and frequencies on levels of superoxide dismutases and malondialdehyde in vascular endothelial cells. Zhonghua Jie He He Hu Xi Za Zhi 34(5):371-374 
39. Feng J, Chen BY, Guo MN et al (2007) Changes of nuclear factorkappaB and intercellular adhesion molecule-1 in endothelial cells exposed to various intermittent hypoxia. Zhonghua Jie $\mathrm{He} \mathrm{He} \mathrm{Hu}$ Xi Za Zhi 30(3):202-206

40. Li YM, Chen BY, Feng J et al (2010) Effect of different intermittent hypoxia patterns on interleukin-6 and interleukin-8 levels of human umbilical vein endothelial cells. Zhonghua Er Bi Yan Hou Tou Jing Wai Ke Za Zhi 45(2):139-142

41. Song S, Tan J, Miao Y et al (2017) Effect of different levels of intermittent hypoxia on autophagy of hippocampal neurons. Sleep Breath 21(3):791-798. https://doi.org/10.1007/s11325-017-1512-7

42. Song S, Tan J, Miao Y et al (2018) Intermittent-hypoxia-induced autophagy activation through the ER-stress-related PERK/eIF2 $\alpha$ / ATF4 pathway is a protective response to pancreatic $\beta$-cell apoptosis. Cell Physiol Biochem 51(6):2955-2971. https://doi.org/10. $1159 / 000496047$

43. Xin L, Fan W, Tingting D, Zuoming S, Qiang Z (2019) 4phenylbutyric acid attenuates endoplasmic reticulum stressmediated apoptosis and protects the hepatocytes from intermittent hypoxia-induced injury. Sleep Breath 23(2):711-717

44. Mengque X. (2016) Study of deoxycholic acid-mediated-gut dysbiosis induced intestinal adenoma-adenocarcinoma sequence. In: Bangmao W, editor. Internal medicine of digestive diseases. Tianjin

45. Cao H, Xu M, Dong W et al (2017) Secondary bile acid-induced dysbiosis promotes intestinal carcinogenesis. Int $\mathrm{J}$ Cancer 140(11):2545-2556. https://doi.org/10.1002/ijc.30643

46. Xiang L (2018) Dysbiosis contributes to chronic constipation development in the intestine. In: Kui J, editor. Internal medicine of digestive diseases. Tianjin

47. Liang X, Yin G, Ma Y et al (2016) The critical role of mast cellderived hypoxia-inducible factor- $1 \alpha$ in regulating mast cell function. J Pharm Pharmacol 68(11):1409-1416. https://doi.org/10. 1111/jphp.12622

48. Song J, Chen Z, Geng T et al (2018) Deleting MyD88 signaling in myeloid cells promotes development of adenocarcinomas of the colon. Cancer Lett 433:65-75. https://doi.org/10.1016/j.canlet. 2018.06 .036

49. Zheng R, Ma J, Wang D et al (2018) Chemopreventive effects of silibinin on colitis-associated tumorigenesis by inhibiting IL-6/ STAT3 signaling pathway. Mediat Inflamm 2018:1562010. https://doi.org/10.1155/2018/1562010

50. Wang S, Dong W, Liu L et al (2019) Interplay between bile acids and the gut microbiota promotes intestinal carcinogenesis. Mol Carcinog 58(7):1155-1167. https://doi.org/10.1002/mc.22999

51. Tao L, Yang JK, Gu Y et al (2015) Weichang'an and 5fluorouracil suppresses colorectal cancer in a mouse model. World J Gastroenterol 21(4):1125-1139. https://doi.org/10. 3748/wjg.v21.i4.1125

52. Xue H, Xiao Z, Zhang J et al (2013) Disruption of the Dapper3 gene aggravates ureteral obstruction-mediated renal fibrosis by amplifying Wnt/ $\beta$-catenin signaling. J Biol Chem 288(21): 15006-15014. https://doi.org/10.1074/jbc.M113.458448

53. Aono S, Hatanaka A, Hatanaka A et al (2019) $\beta$-Catenin/TCF4 complex-mediated induction of the NRF3 (NFE2L3) gene in cancer cells. Int J Mol Sci 20(13). https://doi.org/10.3390/ ijms20133344

54. Deng S, Wang A, Chen X et al (2019) HBD inhibits the development of colitis-associated cancer in mice via the IL-6R/STAT3 signaling pathway. Int J Mol Sci:20(5). https://doi.org/10.3390/ ijms20051069

55. Miyamoto S, Komiya M, Fujii G et al (2017) Preventive effects of heat-killed Enterococcus faecalis strain EC-12 on mouse intestinal tumor development. Int J Mol Sci:18(4). https://doi.org/10.3390/ ijms 18040826
56. Whitehead RH, Robinson PS (2009) Establishment of conditionally immortalized epithelial cell lines from the intestinal tissue of adult normal and transgenic mice. Am J Physiol Gastrointest Liver Physiol 296(3):G455-G460. https://doi.org/10.1152/ajpgi.90381. 2008

57. Liu LX, Lu H, Luo Y et al (2002) Stabilization of vascular endothelial growth factor mRNA by hypoxia-inducible factor 1 . Biochem Biophys Res Commun 291(4):908-914

58. Semenza GL (2012) Hypoxia-inducible factors: mediators of cancer progression and targets for cancer therapy. Trends Pharmacol Sci 33(4):207-214

59. Semenza GL (2013) HIF-1 mediates metabolic responses to intratumoral hypoxia and oncogenic mutations. J Clin Invest 123(9):3664-3671

60. Xue X, Shah YM (2013) Hypoxia-inducible factor- $2 \alpha$ is essential in activating the COX2/mPGES-1/PGE2 signaling axis in colon cancer. Carcinogenesis. 34(1):163-169

61. Santoyo-Ramos P, Likhatcheva M, García-Zepeda EA, Castañeda-Patlán MC, Robles-Flores M (2014) Hypoxiainducible factors modulate the stemness and malignancy of colon cancer cells by playing opposite roles in canonical Wnt signaling. PLoS One 9(11):e112580

62. Krishnamachary B, Zagzag D, Nagasawa $\mathrm{H}$ et al (2006) Hypoxiainducible factor-1-dependent repression of E-cadherin in von HippelLindau tumor suppressor-null renal cell carcinoma mediated by TCF3, ZFHX1A, and ZFHX1B. Cancer Res 66(5):2725-2731

63. To SK, Zeng WJ, Zeng JZ, Wong AS (2014) Hypoxia triggers a Nur77- $\beta$-catenin feed-forward loop to promote the invasive growth of colon cancer cells. Br J Cancer 110(4):935-945

64. Baba Y, Nosho K, Shima K et al (2010) HIF1A overexpression is associated with poor prognosis in a cohort of 731 colorectal cancers. Am J Pathol 176(5):2292-2301

65. Liu M, Du K, Fu Z, Zhang S, Wu X (2015) Hypoxia-inducible factor 1-alpha up-regulates the expression of phospholipase D2 in colon cancer cells under hypoxic conditions. Med Oncol 32(1):394

66. Ma X, Zhang H, Xue X, Shah YM (2017) Hypoxia-inducible factor $2 \alpha$ (HIF-2 $\alpha$ ) promotes colon cancer growth by potentiating Yes-associated protein 1 (YAP1) activity. J Biol Chem 292(41): 17046-17056

67. Dang DT, Chen F, Gardner LB et al (2006) Hypoxia-inducible factor-1alpha promotes nonhypoxia-mediated proliferation in colon cancer cells and xenografts. Cancer Res 66(3):1684-1936

68. Lavie L (2003) Obstructive sleep apnoea syndrome-an oxidative stress disorder. Sleep Med Rev 7(1):35-51

69. Goodday RH, Bourque SE, Edwards PB (2016) Objective and subjective outcomes following maxillomandibular advancement surgery for treatment of patients with extremely severe obstructive sleep apnea (Apnea-Hypopnea Index >100). J Oral Maxillofac Surg 74(3):583-589

70. Martinez CA, Kerr B, Jin C, Cistulli PA, Cook KM (2019) Obstructive sleep apnea activates HIF-1 in a hypoxia dosedependent manner in HCT116 colorectal carcinoma cells. Int J Mol Sci 20(2)

71. Cadigan KM, Liu YI (2006) Wnt signaling: complexity at the surface. J Cell Sci 119(Pt 3):395-402. https://doi.org/10.1242/ jcs.02826

72. Kraus S, Arber N (2009) Inflammation and colorectal cancer. Curr Opin Pharmacol 9(4):405-410. https://doi.org/10.1016/j.coph. 2009.06.006

73. Johnson DE, O'Keefe RA, Grandis JR (2018) Targeting the IL-6/ JAK/STAT3 signalling axis in cancer. Nat Rev Clin Oncol 15(4): 234-248. https://doi.org/10.1038/nrclinonc.2018.8

74. Bollrath J, Phesse TJ (2009) von BVA, et al. gp130-mediated Stat3 activation in enterocytes regulates cell survival and cell-cycle progression during colitis-associated tumorigenesis. Cancer Cell 15(2):91102. https://doi.org/10.1016/j.ccr.2009.01.002 
75. Huber S, Gagliani N, Zenewicz LA et al (2012) IL-22BP is regulated by the inflammasome and modulates tumorigenesis in the intestine. Nature 491(7423):259-263. https://doi.org/10.1038/ nature 11535

76. Jauch D, Martin M, Schiechl G et al (2011) Interleukin 21 controls tumour growth and tumour immunosurveillance in colitisassociated tumorigenesis in mice. Gut 60(12):1678-1686. https://doi.org/10.1136/gutjnl-2011-300612

77. Kirchberger S, Royston DJ, Boulard O et al (2013) Innate lymphoid cells sustain colon cancer through production of interleukin22 in a mouse model. J Exp Med 210(5):917-931. https://doi.org/ 10.1084/jem.20122308

78. Kryczek I, Lin Y, Nagarsheth $\mathrm{N}$ et al (2014) IL-22(+)CD4(+) T cells promote colorectal cancer stemness via STAT3 transcription factor activation and induction of the methyltransferase DOT1L. Immunity 40(5):772-784. https://doi.org/10.1016/j.immuni.2014.03.010

79. Putoczki TL, Thiem S, Loving A et al (2013) Interleukin-11 is the dominant IL-6 family cytokine during gastrointestinal tumorigenesis and can be targeted therapeutically. Cancer Cell 24(2):257271. https://doi.org/10.1016/j.ccr.2013.06.017

80. Stolfi C, Rizzo A, Franzè E et al (2011) Involvement of interleukin-21 in the regulation of colitis-associated colon cancer. J Exp Med 208(11):2279-2290. https://doi.org/10.1084/jem. 20111106

81. Vadde R, Vemula S, Jinka R, Merchant N, Bramhachari PV, Nagaraju GP (2017) Role of hypoxia-inducible factors (HIF) in the maintenance of stemness and malignancy of colorectal cancer. Crit Rev Oncol Hematol 113:22-27

82. Qiu YY, Hu SJ, Bao YJ et al (2015) Anti-angiogenic and antiproliferative effects of inhibition of HIF- $1 \alpha$ by p-HIF- $1 \alpha$ RNAi in colorectal cancer. Int J Clin Exp Pathol 8(7):7913-7920

83. Newton IP, Kenneth NS, Appleton PL, Näthke I, Rocha S (2010) Adenomatous polyposis coli and hypoxia-inducible factor-1 \{alpha\} have an antagonistic connection. Mol Biol Cell 21(21): 3630-3638

84. Xue X, Jungles K, Onder G, Samhoun J, Győrffy B, Hardiman KM (2016) HIF-3 $\alpha 1$ promotes colorectal tumor cell growth by activation of JAK-STAT3 signaling. Oncotarget. 7(10):11567-11579

85. Nishimoto A, Kugimiya N, Hosoyama T, Enoki T, Li TS, Hamano K (2014) HIF-1 $\alpha$ activation under glucose deprivation plays a central role in the acquisition of anti-apoptosis in human colon cancer cells. Int J Oncol 44(6):2077-2084

86. Tripathi A, Melnik AV, Xue J et al (2018) Intermittent hypoxia and hypercapnia, a hallmark of obstructive sleep apnea, alters the gut microbiome and metabolome. mSystems 3(3)

87. Moreno-Indias I, Torres M, Montserrat JM et al (2015) Intermittent hypoxia alters gut microbiota diversity in a mouse model of sleep apnoea. Eur Respir J 45(4):1055-1065

88. Ko CY, Hu AK, Chou D et al (2019) Analysis of oral microbiota in patients with obstructive sleep apnea-associated hypertension. Hypertens Res

89. Lu D, Yao X, Abulimiti A et al (2018) Profiling of lung microbiota in the patients with obstructive sleep apnea. Medicine (Baltimore) 97(26):e11175

90. Durgan DJ, Ganesh BP, Cope JL et al (2016) Role of the gut microbiome in obstructive sleep apnea-induced hypertension. Hypertension. 67(2):469-474

91. Durgan DJ (2017) Obstructive sleep apnea-induced hypertension: role of the gut microbiota. Curr Hypertens Rep 19(4):35

92. Moreno-Indias I, Torres M, Sanchez-Alcoholado L et al (2016) Normoxic recovery mimicking treatment of sleep apnea does not reverse intermittent hypoxia-induced bacterial dysbiosis and lowgrade endotoxemia in mice. Sleep. 39(10):1891-1897
93. Ko CY, Fan JM, Hu AK et al (2019) Disruption of sleep architecture in Prevotella enterotype of patients with obstructive sleep apnea-hypopnea syndrome. Brain Behav:e01287

94. Ohigashi S, Sudo K, Kobayashi D et al (2013) Changes of the intestinal microbiota, short chain fatty acids, and fecal $\mathrm{pH}$ in patients with colorectal cancer. Dig Dis Sci 58(6):1717-1726

95. Chen HM, Yu YN, Wang JL et al (2013) Decreased dietary fiber intake and structural alteration of gut microbiota in patients with advanced colorectal adenoma. Am J Clin Nutr 97(5):1044-1052

96. Payne AN, Chassard C, Lacroix C (2012) Gut microbial adaptation to dietary consumption of fructose, artificial sweeteners and sugar alcohols: implications for host-microbe interactions contributing to obesity. Obes Rev 13(9):799-809

97. Arumugam M, Raes J, Pelletier E et al (2011) Enterotypes of the human gut microbiome. Nature. 473(7346):174-180

98. Huycke MM, Gaskins HR (2004) Commensal bacteria, redox stress, and colorectal cancer: mechanisms and models. Exp Biol Med (Maywood) 229(7):586-597

99. Muyzer G, Stams AJ (2008) The ecology and biotechnology of sulphate-reducing bacteria. Nat Rev Microbiol 6(6):441-454

100. Xu DZ, Lu Q, Kubicka R et al (1999) The effect of hypoxia/ reoxygenation on the cellular function of intestinal epithelial cells. J Trauma 46(2):280-285. https://doi.org/10.1097/00005373199902000-00014

101. Wells CL, VandeWesterlo EM, Jechorek RP et al (1996) Effect of hypoxia on enterocyte endocytosis of enteric bacteria. Crit Care Med 24(6):985-991. https://doi.org/10.1097/00003246199606000-00019

102. Barbosa T, Rescigno M (2010) Host-bacteria interactions in the intestine: homeostasis to chronic inflammation. Wiley Interdiscip Rev Syst Biol Med 2(1):80-97. https://doi.org/10.1002/wsbm.48

103. Zhong A, Xiong X, Shi M et al (2016) Roles of interleukin (IL)-6 gene polymorphisms, serum IL-6 levels, and treatment in obstructive sleep apnea: a meta-analysis. Sleep Breath 20(2):719-731. https://doi.org/10.1007/s11325-015-1288-6

104. Bauters FA, Hertegonne KB, De Buyzere ML et al (2019) Phenotype and risk burden of sleep apnea: a population-based cohort study. Hypertension 74(4):1052-1062. https://doi.org/10. 1161/HYPERTENSIONAHA.119.13452

105. Bozic J, Borovac JA, Galic T et al (2018) Adropin and inflammation biomarker levels in male patients with obstructive sleep apnea: a link with glucose metabolism and sleep parameters. J Clin Sleep Med 14(7):1109-1118. https://doi.org/10.5664/jcsm.7204

106. Motamedi V, Kanefsky R, Matsangas P et al (2018) Elevated tau and interleukin-6 concentrations in adults with obstructive sleep apnea. Sleep Med 43:71-76. https://doi.org/10.1016/j.sleep.2017.11.1121

107. Abdel-Fadeil MR, Abedelhaffez AS, Makhlouf HA et al (2017) Obstructive sleep apnea: influence of hypertension on adiponectin, inflammatory markers and dyslipidemia. Pathophysiology 24(4): 305-315. https://doi.org/10.1016/j.pathophys.2017.08.003

108. Campos-Rodriguez F, Asensio-Cruz MI, Cordero-Guevara J et al (2019) Effect of continuous positive airway pressure on inflammatory, antioxidant, and depression biomarkers in women with obstructive sleep apnea: a randomized controlled trial. Sleep 42(10). https://doi.org/10.1093/sleep/zsz145

109. Borges YG, LHC C, Aires R et al (2019) Oxidative stress and inflammatory profiles in obstructive sleep apnea: are short-term CPAP or aerobic exercise therapies effective? Sleep Breath. https://doi.org/10.1007/s11325-019-01898-0

Publisher's note Springer Nature remains neutral with regard to jurisdictional claims in published maps and institutional affiliations. 